Bucknell University

Bucknell Digital Commons

Faculty Journal Articles

Faculty Scholarship

2020

\title{
Can I Have your Number? Men's Perceived Effectiveness of Pick- up Lines Used by Women
}

\author{
Maryanne L. Fisher \\ St. Mary's University \\ Sarah Coughlin \\ St. Mary's University \\ T. Joel Wade \\ Bucknell University, jwade@bucknell.edu
}

Follow this and additional works at: https://digitalcommons.bucknell.edu/fac_journ

Part of the Social Psychology Commons

\section{Recommended Citation}

Fisher, Maryanne L.; Coughlin, Sarah; and Wade, T. Joel. "Can I Have your Number? Men's Perceived Effectiveness of Pick-up Lines Used by Women." (2020) .

This Article is brought to you for free and open access by the Faculty Scholarship at Bucknell Digital Commons. It has been accepted for inclusion in Faculty Journal Articles by an authorized administrator of Bucknell Digital Commons. For more information, please contact dcadmin@bucknell.edu. 


\title{
Can I have your number? Men's perceived effectiveness of pick-up lines used by women
}

\author{
Maryanne L. Fisher ${ }^{\mathrm{a}, *}$, Sarah Coughlin ${ }^{\mathrm{a}}$, T. Joel Wade ${ }^{\mathrm{b}}$ \\ ${ }^{a}$ Department of Psychology, Saint Mary's University, Halifax, Canada \\ ${ }^{\mathrm{b}}$ Department of Psychology, Bucknell University, Lewisburg, Pennsylvania, USA
}

\section{A R T I C L E I N F O}

\section{Keywords:}

\section{Flirting}

Sex differences

Mating

Attractiveness

Courtship

\begin{abstract}
A B S T R A C T
We examined which pick-up lines that women may use on men, in the context of dating, are the most effective. Effectiveness was defined as success in securing a phone number or agreeing to meet again. We tested to determine which type of line (direct, innocuous, or flippant) was rated as most effective when attractiveness and perceived promiscuity of the women were manipulated. We predicted that direct pick-up lines would be the most effective when trying to pick-up men for the purpose of dating. We also predicted that men would rate the pickup lines used by women rated high on attractiveness and promiscuity as being more effective than the pick-up lines used by those rated low on both characteristics. Results indicate that direct pick-up lines are preferred over flippant or innocuous pick-up lines, with the innocuous being the least preferred. Further, regardless of the line that is used, once a woman has been viewed as attractive by men, she is rated positively. This study provides insight into the effectiveness of women's tactics for soliciting dating attention.
\end{abstract}

\section{Introduction}

The initial communication that occurs between prospective romantic partners is critical in determining whether an interaction, and subsequent relationship will continue or not. Such communications often tend to be covert, with the ability to create signals and to accurately receive them being key for success (e.g., White, Lorenz, Perilloux, \& Lee, 2018). Flirting, including the use of pick-up lines, conveys interest in a potential partner, and communicates that one wishes to establish intimacy, to express sexual intentions, or to state relationship expectations (e.g., Weber, Goodboy, \& Cayanus, 2010). Here we solely focus on one part of flirting: the use of pick-up lines.

The overwhelming majority of research on pick-up lines pertains to how men commonly use them to encourage conversation with women in the hopes of securing a date (Kleinke, Meeker, \& Staneski, 1986; Senko \& Fyffe, 2010). There is a variety of lines one can use, which have been categorized in many ways; here we use the categories of direct, innocuous, and flippant (Kleinke et al., 1986; see also Weber et al., 2010). Direct lines clearly convey interest, for example, "You're hot, can I have your number?" Innocuous lines hide the intention of the speaker and act more as conversation starters, such as, "Can you recommend a good drink?" Flippant lines are humourous, for example, "Can I get a picture of you so I can show Santa what I want for Christmas?" The innocuous and flippant lines are theorized to protect the user from rejection, as they can disguise a failed attempt as a simple question or a joke (Kleinke et al., 1986). Flippant lines display creativity via humour, which mate preference literature indicates that men who produce humour are viewed positively (e.g., Bressler, Martin, \& Balshine, 2006; Hone, Hurwitz, \& Lieberman, 2015), and that it indicates mental fitness (Howrigan \& MacDonald, 2008).

Generally, women in Westernized cultures are most receptive to innocuous lines followed by direct lines, and are least receptive to flippant lines (Kleinke et al., 1986; but see also Cunningham, 1989, no distinction between innocuous and direct lines). Cunningham (1989) proposes that women may perceive flippant line users as unintelligent or untrustworthy. Likewise, Kleinke and Dean (1990) report both men and women view flippant line users as the least likeable and responsible, as well as being the most selfish, domineering, and promiscuous. Men, however, were most receptive to direct lines, followed by flippant lines, and least receptive to innocuous lines (Kleinke et al., 1986). Men's dislike of innocuous lines may be due to the lines not explicitly conveying intent. Hence, men are unable to determine if the woman using the line was interested in more than a conversation. For both men and women, users of direct lines are perceived as being the most likeable and responsible, as well as being the least selfish (Kleinke \& Dean, 1990). Cunningham (1989) and Kleinke et al. (1986), however, found that men were generally positive toward all three categories. This finding is not surprising since men are opportunistic maters (Buss \&

\footnotetext{
* Corresponding author.

E-mail address: mlfisher@smu.ca (M.L. Fisher).
} 
Schmitt, 1993). Men tend to rate the flippant line users as being more likeable and promiscuous, as well as less selfish and domineering, than do women (Kleinke \& Dean, 1990). Similarly, Weber et al. (2010) found that third-party and direct introductions were the most effective interaction. Consistent with Kleinke et al. (1986) and Cunningham (1989), humor attempts and cute-flippant lines were preferred the least. Perhaps so-called cute flippant lines, while conveying humour, do not convey creative humour which signals mental fitness (Howrigan \& MacDonald, 2008).

Senko and Fyffe (2010) proposed that the effectiveness of pick-up lines varies according to whether one is being considered for short-term versus long-term relationships. They studied women's imagined responses to men using pick-up lines and manipulated the men's physical attractiveness. When considering men for a long-term relationship, women were less likely to converse with a man if he used a flippant line. Women were most likely to converse with a man, and consider him for a long-term relationship, if he was attractive. Attractiveness was critical when considering a man for a short-term relationship with the type of line used exerting minimal influence. Overall, men who used innocuous lines were judged to be less sociable than men who used direct or flippant lines. However, men who used flippant lines were judged as funnier, more confident, and more sociable than men using direct or innocuous lines, but were also judged as being unintelligent and untrustworthy (Senko \& Fyffe, 2010). Sexually based flippant pickup lines are consistently rated as unappealing (Bale, Morrison, \& Caryl, 2006; Cooper et al., 2007; Cunningham, 1989; Kleinke et al., 1986).

Wade, Butrie, and Hoffman (2009) research is noteworthy because they examined the perceived effectiveness of women using pick-up lines on men. They found participants rated direct lines (i.e., directly asking for a date) to be the most popular, followed by hinting at a date (i.e., implying a date but not directly asking), and third, subtly saying "hello." Sexual humor was the least popular. In another study, participants rated pick-up lines based on whether they effectively communicated a woman's interest in dating or spending time together. The results showed that the most effective lines were those asking about romantic relationship status, or providing/requesting a phone number (Wade et al., 2009). These studies were performed on young adults in the United States, which is a culturally comparable group to our sample of young adults in Eastern Canada.

Researchers, including Wade et al. (2009), have historically focused more on the pick-up lines rather than the appearance of the people using them. Characteristics such as attractiveness should alter the effectiveness of the pick-up lines, given physical appearance influences perceptions of sociability and intelligence (Guéguen, 2010). Attractiveness is of particular importance for women, given men generally prefer attractive women (e.g., Buss, 1988), and consider interactions with attractive women more positively than those with less attractive women (Berry \& Miller, 2001). The purpose of using pick-up lines is to secure a date, and dating serves the function of relationship formation and mate selection (Buss \& Schmitt, 1993). Hence, physical appearance (i.e., attractiveness and promiscuity of clothing) of a woman using a pick-up line is expected to influence the response of the man hearing the line. We note that the existing empirical results are mixed; Shanteau and Nagy (1979) found that when willingness to accept an offer of a date was guaranteed, physical appearance did not play a significant role. Likewise, Snyder, Berscheid, and Glick (1985) report that self-monitoring is key, given that low self-monitors are more likely to select dates based on personality while high self-monitors more readily factor in attractiveness.

Although women may control the initial interactions, one can argue that Western society puts pressure on men to act first within a dating context (Bredow, Cate, \& Huston, 2008). The traditional flirting style follows stereotypical gender roles, where men are seen as the aggressor in the relationship and are expected to initiate the first interaction and facilitate future contact (Hall, Carter, Cody, \& Albright, 2010). Women tend to allow this flirting style as it protects them from rejection; unfortunately, this attitude is considered benevolent sexism and perpetuates gender inequality (Hall et al., 2010; Viki, Abrams, \& Hutchison, 2003). Men who do not identify with the traditional flirting style, however, are more willing to allow women to initiate contact as there are more perceived benefits, such as the invitation of sex (Hall et al., 2010).

The dearth of research addressing women's use of pick-up lines is interesting, because past findings indicate that women generally control initial interactions within a dating context. When a man approaches a woman who has not yet noticed him, he tends not to be successful (Renninger, Wade, \& Grammer, 2004). Indeed, women use a protean strategy appearing to exert control without the majority of men recognizing this control (Grammer, Kruck, Juette, \& Fink, 2000). Therefore, the gap in the literature that our study specifically seeks to address is women's use of pick-up lines, and more specifically, the effectiveness of various types of pick-up lines when the user's perceived attractiveness and promiscuousness are considered.

\section{Current studies}

The goal of the current study was to examine men's perception of the effectiveness of women's pick-up lines, and to consider how that effectiveness may be influenced by women's attractiveness and promiscuity. There were two hypotheses for the current study. Hypothesis 1 was that women using direct pick-up lines would be rated as being the most effective when trying to pick-up men for the purpose of dating. Studies by Kleinke et al. (1986) and Wade et al. (2009) found that both men and women rated direct pick-up lines as being the most effective because the speaker's intent is clear. Hypothesis 2 was that men would rate the pick-up lines used by highly attractive women dressed in a highly promiscuous way as more effective than the pick-up lines used by women who were less attractive and promiscuous. Hypothesis 2 was based on the literature that indicates men generally choose their mates based on their reproductive potential (i.e., youth, attractiveness, and health), as well as how sexually available (i.e., how promiscuous or revealing the clothing) they are to the perceiver (Buss \& Schmitt, 1993). Also, in a study on attitudes toward sexually permissive women, men were found to rate attractive women more positively than they would unattractive women (Janda, O'Grady, \& Barnhart, 1981). In other words, given a choice, men will prefer to date attractive women who are promiscuous.

We conducted two pilot studies and then the main experiment, all of which received ethics approval from an institutional review board. The goal of Pilot Study 1 was to ascertain whether women actually use pickup lines to acquire mating interest, and if so, what sorts of lines they employ. We used Pilot Study 2 to determine which photographs to include in the actual experiment. The experiment tested Hypothesis 1 and 2 , listed above. As previously discussed, while the literature has mainly focused on pick-up lines used by men (e.g., Senko \& Fyffe, 2010), our experiment was designed to focus exclusively on the effectiveness of women's use of pick-up lines on men, in the context of dating. Effectiveness was defined as either success in starting a conversation or securing future contact with the recipient (e.g., exchange of phone numbers, plans to meet again). The pick-up lines, viewed from men's perspective, took one of three forms, in keeping with Kleinke et al. (1986): direct, flippant, and innocuous, as previously described. Specifically, this research attempts to fill the void in the literature dealing with the influence of women's characteristics (i.e., promiscuousness) and clothing on the perceived effectiveness of pickup lines.

\section{Pilot study 1}

Pilot Study 1 was conducted to ensure women actually use pick-up lines, and if so, which types of lines. We used a convenience sample of 18 self-reported heterosexual female friends and colleagues between 
the ages of 18 and 31 years $\left(M_{\text {age }}=21.5\right)$. Participants were approached by e-mail or through private social media communications, using the script:

Every time I am at [Name of Bar] with my friends I see this guy, I think he might work there. I really want to talk to him, what should I do?

The script was informal and phrased in a way that participants believed they were being asked for real advice so the responses would be honest. Participants were debriefed after they provided their response.

Results ranged from "I do not know," to "Go up to him and tell him he is hot." The most frequently provided response was "Go up to him, say hi, and [start a conversation]." This answer fell between innocuous and direct, as the ways to begin the conversation varied, and was included in the experimental study as the innocuous line "Hi". Results from this pilot study were consistent with pick-up lines used in other studies (Kleinke et al., 1986; Senko \& Fyffe, 2010). The pick-up lines that were used in the experimental study from the pilot study consisted of the innocuous lines: "Can you recommend a good drink?", "I've seen you before, do you work here?", "Where did you get that tattoo? Did it hurt?", or "Hi". Direct lines were: "Want to have a drink together?", "You have really nice eyes", "Can I have your number?", and "You're cute." Flippant lines included: "Shall we talk, or continue flirting from a distance", "I always see you here, you must be the bar's best customer!", "Since you're alone and I'm alone, why don't we sit together?", and "I'm easy, are you?"

\section{Pilot study 2}

Pilot Study 2 was used to determine which subsets of photographs best represented the four combinations of high versus low attractiveness and high versus low promiscuousness; these photographs were to be used in the experiment. Participants consisted of 205 self identifying heterosexual men, mostly Caucasian, between the ages 18 and 53 years $\left(M_{\text {age }}=27.8, S D_{\text {age }}=7.60\right)$. They were recruited through the web forum Reddit via an advertisement that asked for help in rating women's photographs for experimental stimuli. We selected Reddit due to convenience (i.e., quick participant recruitment) and popularity within the United States and Canada (i.e., Reddit is the third most popular Internet site in the United States, behind only YouTube and Google; Nguyen, 2018).

After providing informed consent, participants were shown 27 colour photographs of women dressed in clothing that varied in terms of the amount of skin revealed, and/or tightness. Full body photographs were used, with the models appearing to be in their early to late twenties, and the majority (i.e., all but three) appeared to be primarily Caucasian. Photographs were collected from various online sources (e.g., Bing.com, sears.com, lechateau.com). We selected photographs from these sources in an effort to control for external factors (e.g., backgrounds, posing, style of photography) while also locating models wearing clothes that varied in how much of the body was revealed.

Participants were presented with two Likert-type scales and asked to indicate their level of agreement. Item one asked if the woman in the photograph was attractive ( $1=$ strongly disagree, $7=$ strongly agree) and item two asked if the woman was promiscuous $(1=$ strongly disagree, $7=$ strongly agree). The ratings allowed us to then select 12 photographs, such that three photographs fit each of the four conditions: high attractiveness/low promiscuousness, high attractiveness/ high promiscuousness, low attractiveness/high promiscuousness, low attractiveness/low promiscuousness.

Using descriptive statistics (i.e., mean, mode, and standard deviation), we determined which photographs to include as stimuli in the experiment. For all of the photographs, the cut off mark for high attractiveness or high promiscuousness was $M=4.00$ and above, and anything below considered as low attractiveness or low promiscuousness. Mode was considered in cases where multiple photographs had similar mean ratings. Only the photographs that best fit the categories were chosen, and were further agreed upon by two independent raters.

\section{The experiment}

The aim of the current research was to investigate how effectively men perceive women's pick-up lines, and to explore how that effectiveness may be influenced by women's attractiveness and promiscuity, via testing of the two aforementioned hypotheses (i.e., Hypothesis 1, that direct pick-up lines are the most used and Hypothesis 2, that men rate pick-up lines as most effective when used by highly attractive women dressed promiscuously).

\subsection{Methods}

\subsubsection{Participants}

The participants consisted of 130 heterosexual men between the ages of 18 and $56\left(M_{\text {age }}=24.45, S D_{\text {age }}=6.09\right)$ who were solicited via Reddit. The advertisement asked for heterosexual volunteers over 18 years old for a study on pick-up lines used by women. The sample was dominated by those currently living in Canada (23.4\%) and the United States $(46.1 \%)$. A total of $30.8 \%$ reported they had completed an undergraduate university degree or higher. When invited to disclose their ethnicity, $77.8 \%$ of participants indicated via self-identification that they were White, while the second most frequent ethnicity was European at 7.1\% (including Northern European, Germanic, Croatian, Ukrainian, and British). About half of the participants were single (51.5\%), followed by those in a committed, monogamous dating relationship (20.8\%), and then those currently married or in a commonlaw relationship (17.7\%).

\subsubsection{Measures}

The questionnaire consisted of 12 photographs of women, as determined via Pilot Study 2, with three women representing each of the four conditions detailed earlier. An image of a woman was shown along with a pick-up line, using multiple versions of the survey to ensure random presentation. For the three photographs within each condition, one was accompanied by an innocuous line, one by a direct line, and one by a flippant line, using the lines obtained from Pilot Study 1. Using a seven item Likert-type scale $(1=$ strongly disagree, $7=$ strongly agree), participants rated their agreement with the statement, "This pick-up line is effective."

\subsubsection{Procedure}

Participants clicked on the Reddit post and were redirected to Qualtrics, where they provided informed consent. They completed a demographic survey and the Kinsey scale measuring sexual orientation (all included participants stated they were predominantly or exclusively heterosexual, and over 18). Participants were presented with a picture of a "local" bar (image found via Bing) and a story for context:

A few months ago, we recorded women who were trying to pick up men at this bar in Toronto, Canada. We wrote some of these lines down, and now ask you to rate each line on how effective it would be. We include a photo of each woman and the line she used.

After the story, participants were directed to the questionnaire, then debriefed.

\subsection{Results}

We created a repeated measures Multivariate Analysis of Variance (MANOVA) model, with two within-subject factors. One factor had four levels to represent the four conditions (i.e., high attractiveness/high promiscuousness, high attractiveness/low promiscuousness, low attractiveness/high promiscuousness, and low attractiveness/low promiscuousness) while the other factor had three levels to represent the 
three types of pick-up lines (i.e., direct, innocuous, or flippant). Perceived effectiveness was the dependent variable, with mean effectiveness scores calculated for each of the three types of pick-up lines and four conditions.

There was an overall main effect for condition, $F(3,119)=77.16$, $p<.000, \eta \mathrm{p}^{2}=0.66$. There was likewise an overall main effect for line, $F(2,120)=30.08, p<.000, \eta \mathrm{p}^{2}=0.33$. The interaction term, too, was significant, $F(6,116)=29.94, p<0.000, \eta \mathrm{p}^{2}=0.61$.

Pairwise comparisons for condition revealed the following significant findings. The effectiveness of pick-up lines from women with high attractiveness/high promiscuousness $(M=4.90, S D=1.16)$ was not significantly different from high attractiveness/low promiscuousness $(M=4.84, S D=0.94)$, but was significantly different from low attractiveness/high promiscuousness $(M=4.38, S D=1.10 ; p<.000)$ and from low attractiveness/low promiscuousness $(M=3.25$, $S D=1.11, p<.000$ ). Similarly, high attractiveness/low promiscuousness was significantly different from both low attractiveness/ high promiscuousness and low attractiveness/low promiscuousness, $p<.000$. Last, low attractiveness/high promiscuousness was significantly more effective than low attractiveness/low promiscuousness, $p<.000$.

All of the pairwise comparisons for the type of pickup line were significant. Direct lines were the most effective $(M=4.63, S D=0.93)$, and significantly more so than innocuous $(M=3.97, S D=0.87$, $p<.000)$ and flippant lines $(M=4.43, S D=1.09, p=.025)$. Innocuous lines were significantly less effective than flippant lines, $p<.000$.

The pairwise comparisons for the interactions were all significant to $p<.000$ except those listed in the following section, which were either significant to a different value (i.e., $p<.05$ ) or not significant; descriptives appear in Table 1.

\subsection{High attractiveness/high promiscuousness models}

The effectiveness of high attractiveness/high promiscuousness models using flippant lines was not different from innocuous lines, $p=.52$, but was from direct lines, $p=$ ing flippant lines, $p=.031$.

These models, when using direct lines were significantly different from models with low attractiveness/high promiscuousness using flippant lines, $p=.007$, and from models with high attractiveness/high promiscuousness using innocuous lines, $p=.001$.

Last, when they used innocuous lines they were significantly more effective than models with low attractiveness/low promiscuousness using flippant lines, $p=.043$.

\subsection{High attractiveness/low promiscuousness models}

Models with high attractiveness/low promiscuousness using innocuous lines were significantly different from those with high attractiveness/high promiscuousness using direct lines, $p=.01$, and those

Table 1

Descriptive results regarding attractiveness and promiscuousness.

\begin{tabular}{llll}
\hline Type of line & Characteristics & $M$ & $S D$ \\
\hline \multirow{2}{*}{ Direct } & Low attractiveness/Low promiscuousness & 2.85 & 1.66 \\
& Low attractiveness/High promiscuousness & 4.61 & 1.40 \\
& High attractiveness/Low promiscuousness & 5.80 & 1.00 \\
& High attractiveness/High promiscuousness & 5.27 & 1.39 \\
Innocuous & Low attractiveness/Low promiscuousness & 2.63 & 1.29 \\
& Low attractiveness/High promiscuousness & 3.75 & 1.51 \\
& High attractiveness/Low promiscuousness & 4.87 & 1.46 \\
& High attractiveness/High promiscuousness & 4.66 & 1.66 \\
Flippant & Low attractiveness/Low promiscuousness & 4.27 & 1.78 \\
& Low attractiveness/High promiscuousness & 4.84 & 1.61 \\
& High attractiveness/Low promiscuousness & 3.87 & 1.89 \\
& High attractiveness/High promiscuousness & 4.73 & 1.66 \\
\hline
\end{tabular}

with low attractiveness/low promiscuousness using flippant lines, $p=.004$.

Further, their effectiveness when using innocuous lines was not significantly different from models with high attractiveness/high promiscuousness also using innocuous lines, $p=.24$, or models with low attractiveness/high promiscuousness using flippant lines, $p=.86$, or when the latter use direct lines, $p=.12$.

Last, when they used flippant lines, they did not differ from models with low attractiveness/low promiscuousness using flippant lines, $p=.054$.

\subsection{Low attractiveness/high promiscuousness models}

The effectiveness of models with low attractiveness/high promiscuousness using direct lines was not significantly different from those with low attractiveness/high promiscuousness using flippant lines, $p=.132$. It was different compared to low attractiveness/low promiscuousness models using flippant lines $p=.036$.

Those using innocuous lines and those with high attractiveness/low promiscuousness using flippant lines were not significantly different, $p=.509$. However, their effectiveness was significantly different to models with low attractiveness/low promiscuousness using flippant lines, $p=.01$.

Moreover, they were not significantly different when using direct lines $(p=.73)$ or flippant lines $(p=.36)$ compared to high attractiveness/high promiscuousness models using innocuous lines.

\subsection{Low attractiveness/low promiscuousness models}

The effectiveness of models with low attractiveness/low promiscuousness using direct lines was not significantly different from models with low attractiveness/low promiscuousness using innocuous lines, $p=.16$

\section{Discussion}

Our findings suggest that direct lines are preferred over flippant and innocuous lines, with the innocuous lines being the least preferred. This finding supports Hypothesis 1 and is consistent with the findings of Kleinke et al. (1986). Our results also indicate that attractiveness plays a more significant role than promiscuousness, as indicated by clothing, on the effectiveness of pick-up lines. However, as attractiveness and promiscuousness were not tested in isolation of each other, further testing is certainly needed. Further, Hypothesis 2 was supported in that the women in the high attractiveness and high promiscuousness condition were rated to be the most effective, although there was no difference caused by promiscuity for those using direct lines. The low attractiveness and low promiscuousness condition also led to the lowest perceived effectiveness scores, particularly if matched with an innocuous pick-up line.

Flippant pick-up lines deserve particular attention. When combining the results from the current as well as prior studies on flippant lines with research on humour, there is conflicting information. The results of research on humor suggest that women prefer men who are funny and have a good sense of humor, as it shows off their intelligence and creativity (Bressler et al., 2006; Guéguen, 2010). If this is the case, then the flippant pick-up lines (i.e., the funny lines) should be the most successful of the categories when in reality, they are not. In fact, according to Senko and Fyffe (2010), flippant line users are perceived as unintelligent by women. Research on humor also indicates that men do not particularly like funny women; instead they like women who enjoy their sense of humor (Bressler et al., 2006). These findings suggest that men would be less receptive to flippant lines, but this is not so; men preferred flippant lines more than innocuous lines in the current study (see also Kleinke et al., 1986; Wade et al., 2009; Weber et al., 2010).

To offer insight on why some lines may be better received than 
others, Cooper, O'Donnell, Caryl, Morrison, and Bale (2007) propose that pick-up lines may serve a function besides relationship initiation. Users may administer the lines to assess personality and test to see if the individual they have selected is worth their time. For example, a sexually flippant line may be used to judge how sexually permissive an individual is, or how sexually exploitable an individual may be (Goetz, Easton, Lewis, \& Buss, 2012) by their response. In other words, depending on the line choice, the line user can test for behaviours or personality traits they do or do not desire in a prospective mate.

There were some limitations with the current research, one of which is that the women used in the photographs were all professional clothing models. Thus, the women are not representative of the general population. Further, rating photographs and stated pick-up lines is far less realistic than being approached by women in real-life; prosodic (e.g., intonation) and kinesic (e.g., gestures) communication may make a difference in the way the lines are perceived. Support is provided by Bale et al. (2006) who suggest that results from experimental work may change if researchers perform their studies in real bars, with individuals being presented with the pick-up lines by potential mates. Although Senko and Fyffe (2010) found that their paper and pencil study was just as reliable as a field study, there is always the possibility that real life situations might cause different results.

The reason underlying the effectiveness of direct pick-up lines needs to be further explored. Past researchers have proposed that their effectiveness is due to a lack of ambiguity. If so, then lines that clearly state one's romantic or sexual interest should be the most effective, while those that merely indicate interest should be less effective. However, stating one's intentions immediately may be perceived as being over-eager or desperate, which results in a negative first impression (but see Walster, Walster, Piliavin, \& Schmidt, 1973). Also, a woman stating her intentions directly could lead to a bad mate choice since the woman may need to keep an interaction with a potential mate going for a short time in order to get him to reveal his true characteristics and disposition (see Grammer et al., 2000). Therefore, there needs to be further scrutiny on compromises with respect to content, such that some forms of direct lines are considered better than others.

It may be advantageous to investigate one's preference for long and short-term relationships, as it may influence ratings of pick-up lines' effectiveness. It is possible that individuals currently seeking short-term relationships may rate more lines as being effective than those seeking long-term relationships. This possibility is based on Sexual Strategies Theory, which proposes that individuals relax their standards when pursuing short-term relationships and raise their standards for longterm relationships (Buss \& Schmitt, 1993). Also, some forms of direct lines may be more effective than others in some short term or long term situations.

The current study replicates Wade et al. (2009), who examine the perceived effectiveness of women using direct, innocuous, and flippant pick-up lines on men. Similarly, we found direct lines were perceived as the most effective, followed by flippant, and innocuous. We extended past work to examine the potential influence of women's attractiveness and promiscuousness, as indicated by clothing, and found that attractiveness was more important than promiscuousness except when using a direct pick-up line. Promiscuousness may have had a lesser effect than attractiveness due to recent societal efforts to curtail "slut-shaming" (i.e., labelling women as promiscuous based on their clothing choices and participation in frequent short term mating). Within this movement terms such as "slut" and women's provocative clothing choices are celebrated rather than lambasted (see Attwood, 2007; Ringrose \& Renold, 2012).

\section{References}

Attwood, F. (2007). Sluts and riot grrrls girls?: Female identity and sexual agency. Journal of Gender Studies, 16(3), 231-245. https://doi.org/10.1080/09589230701562921.

Bale, C., Morrison, R., \& Caryl, P. G. (2006). Chat-up lines as male sexual displays. Personality and Individual Differences, 40(4), 655-664. https://doi.org/10.1016/j paid.2005.07.016.

Berry, D. S., \& Miller, K. M. (2001). When boy meets girl: Attractiveness and the fivefactor model in opposite-sex interactions. Journal of Research in Personality, 35(1), 62-77.

Bredow, C. A., Cate, R. M, \& Huston, T. L. (2008). Have we met before? A conceptual model of first romantic encounters. In S. Sprecher, A. Wenzel, \& J. Harvey (Eds.). Handbook of relationship initiation (pp. 3-29). New York: Psychology Press.

Bressler, E. R., Martin, R. A., \& Balshine, S. (2006). Production and appreciation of humor as sexually selected traits. Evolution and Human Behaviour, 27(2), 121-130.

Buss, D. M. (1988). The evolution of human intrasexual competition: Tactics of mate attraction. Journal of Personality and Social Psychology, 54(4), 616-628. https://doi. org/10.1037/0022-3514.54.4.616.

Buss, D. M., \& Schmitt, D. P. (1993). Sexual strategies theory: An evolutionary perspective on human mating. Psychological Review, 100(2), 204-232. https://doi.org/10.1037/ 0033-295X.100.2.204.

Cooper, M., O'Donnell, D., Caryl, P. G., Morrison, R., \& Bale, C. (2007). Chat-up lines as male displays: Effects of content, sex, and personality. Personality and Individual Differences, 43(5), 1075-1085. https://doi.org/10.1016/j.paid.2007.03.001.

Cunningham, M. R. (1989). Reactions to heterosexual opening gambits: Female selectivity and male responsiveness. Personality and Social Psychology Bulletin, 15(1), 27-41. https://doi.org/10.1177/0146167289151003.

Goetz, C. D., Easton, J. A., Lewis, D. M., \& Buss, D. M. (2012). Sexual exploitability: Observable cues and their link to sexual attraction. Evolution and Human Behavior, 33(4), 417-426.

Grammer, K., Kruck, K., Juette, A., \& Fink, B. (2000). Non-verbal behaviour as courtship signals: The role of control and choice in selecting partners. Evolution and Human Behaviour, 21(6), 371-390.

Guéguen, N. (2010). Men's sense of humor and women's responses to courtship solicitations: An experimental field study. Psychological Reports, 107(1), 145-156. https:// doi.org/10.2466/07.17.PR0.107.4.145-156.

Hall, J. A., Carter, S., Cody, M., \& Albright, J. (2010). Individual differences in the communication of romantic interest: Development of the flirting styles inventory. Communication Quarterly, 58(4), 365-393.

Hone, L. S. E., Hurwitz, W., \& Lieberman, D. (2015). Sex differences in preferences for humor: A replication, modification, and extension. Evolutionary Psychology, 13(1) doi: 147470491501300110 .

Howrigan, D. P., \& MacDonald, K. B. (2008). Humor as a mental fitness indicator. Evolutionary Psychology, 6(4), 652-666.

Janda, L. H., O'Grady, K. E., \& Barnhart, S. A. (1981). Effects of sexual attitudes and physical attractiveness on person perception of men and women. Sex Roles, 7(2), 189-199. https://doi.org/10.1007/BF00287805.

Kleinke, C. L., \& Dean, G. O. (1990). Evaluation of men and women receiving positive and negative responses with various acquaintance strategies. Journal of Social Behavior \& Personality, 5(5), 369-377.

Kleinke, C. L., Meeker, F. B., \& Staneski, R. A. (1986). Preference for opening lines: Comparing ratings by men and women. Sex Roles, 15(11-12), 585-600. https://doi. org/10.1007/BF00288216.

Nguyen, C. (2018, May 30). Reddit beats out Facebook to become the third-most-popular site on the web. Digital Trends. Retrieved August 202019 from https://www. digitaltrends.com/computing/reddit-more-popular-than-facebook-in-2018/.

Renninger, L. A., Wade, T. J., \& Grammer, K. (2004). Getting that female glance: Patterns and consequences of male nonverbal behavior in courtship contexts. Evolution and Human Behavior, 25(6), 416-431. https://doi.org/10.1016/j.evolhumbehav.2004.08. 006.

Ringrose, J., \& Renold, E. (2012). Slut-shaming, girl power and 'sexualisation': Thinking through the politics of the international SlutWalks with teen girls. Gender and Education, 24(3), 333-343. https://doi.org/10.1080/09540253.2011.645023.

Senko, C., \& Fyffe, V. (2010). An evolutionary perspective on effective vs. ineffective pickup lines. Journal of Social Psychology, 150(6), 648-667.

Shanteau, J., \& Nagy, G. F. (1979). Probability of acceptance in dating choice. Journal of Personality and Social Psychology, 37(4), 522-533. https://doi.org/10.1037/00223514.37.4.522.

Snyder, M., Berscheid, E., \& Glick, P. (1985). Focusing on the exterior and the interior: Two investigations of the initiation of personal relationships. Journal of Personality and Social Psychology, 48(6), 1427-1439. https://doi.org/10.1037/0022-3514.48.6. 1427.

Viki, G. T., Abrams, D., \& Hutchison, P. (2003). The 'true' romantic: Benevolent sexism and paternalistic chivalry. Sex Roles, 49(9-10), 533-537. https://doi.org/10.1023/ A:1025888824749.

Wade, J. T., Butrie, L. K., \& Hoffman, K. M. (2009). Women's direct opening lines are perceived as most effective. Personality and Individual Differences, 47(2), 145-149.

Walster, E., Walster, G. W., Piliavin, J., \& Schmidt, L. (1973). Playing hard to get': Understanding an elusive phenomenon. Journal of Personality and Social Psychology, 26(1), 113-121.

Weber, K., Goodboy, A. K., \& Cayanus, J. L. (April 01, 2010). Flirting competence: An experimental study on appropriate and effective opening lines. Communication Research Reports, 27(2), 184-191.

White, J., Lorenz, H., Perilloux, C., \& Lee, A. (2018). Creative Casanovas: Mating strategy predicts using - but not preferring - atypical flirting tactics. Evolutionary Psychological Science, 4(4), 443-455. 